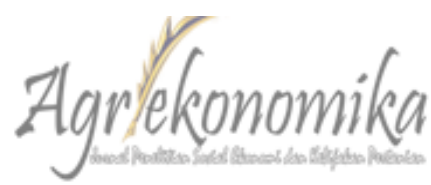

Jurnal Sosial Ekonomi dan Kebijakan Pertanian

http://journal.trunojoyo.ac.id/agriekonomika

Agriekonomika Volume 5, Nomor 2, 2016

\title{
MODEL KERJASAMA KELOMPOK PEMBUDIDAYA IKAN (POKDAKAN) PADA PEMASARAN AGRIBISNIS IKAN GURAMI DI KABUPATEN BANYUMAS
}

\author{
Yusuf Enril Fathurrohman \\ Prodi Agribisnis Fakultas Pertanian, Universitas Muhammadiyah Purwokerto \\ yusuf.enril@gmail.com
}

Received: 15 September 2016; Accepted: 14 Oktober 2016; Published: 30 Oktober 2016

DOI: http://dx.doi.org/10.21107/agriekonomika.v5i2.1750

\begin{abstract}
ABSTRAK
Tujuan penelitian ini untuk mengetahui pola kerjasama antara POKDAKAN dengan pembudidaya ikan gurami dalam bidang pemasaran yang dijabarkan melalui analisis deskriptif. Penelitian ini menggunakan metode studi kasus melalui wawancara dengan pembudidaya gurami anggota POKDAKAN dan pengurus POKDAKAN. Hasil dari penelitian ini menunjukkan bahwa melalui kerjasama antara POKDAKAN dan pembudidaya ikan diperoleh keuntungan 1) pembudidaya ikan gurami memperoleh ketersediaan faktor produksi seperti kolam, bibit, pakan dan SDM pengawasan; 2) POKDAKAN memperoleh ketersediaan ikan gurami konsumsi untuk dipasarkan dan keuntungan sebesar $15 \%$ dari hasil penjualan, 3) calon pembeli memperoleh barang (ikan gurami) dengan akses mudah (one spot service) dan memperoleh kualitas dan kuantitas yang diinginkan serta terjaganya kontinuitas pemasaran.
\end{abstract}

Kata Kunci: POKDAKAN, ikan gurami, pemasaran, kerjasama.

PATNERSHIP MODEL OF FISH FARMER GROUP (POKDAKAN) AGAINTS GOURAMY-AGRIBUSINESS MARKETING IN BANYUMAS

\begin{abstract}
The purpose of this study to determine the pattern of cooperation between POKDAKAN with gouramy farmers in marketing area which is explained by the descriptive analysis. This study uses a case study through interviews with gourami farmers as members of POKDAKAN and the officer of POKDAKAN. The results of this study indicate that through cooperation between POKDAKAN and gourami farmers earned benefits such as gourami farmers acquire the availability of production factors such as ponds, seed, feed and human supervision; 2) POKDAKAN obtain availability of gourami to be marketed and profits by $15 \%$ of the sales, 3) prospective buyers obtain gourami with easy access (one spot service) and obtain the desired quality and quantity as well as the preservation of continuity marketing.
\end{abstract}

Keywords: POKDAKAN, gourami, marketing, cooperation.

\section{PENDAHULUAN}

Perikanan merupakan salah satu subsektor pertanian yang memiliki peran penting sebagai penggerak kemajuan

Corresponding author

Address : Jl. Damar IV No. 56, Perumahan Teluk Pur wokerto Selatan, Banyumas, JATENG

Email : yusuf.enril@gmail.com

Phone : 085291276191 perekonomian nasional di Indonesia. Apabila ditinjau dari aspek ekonomi, menurut data dari Badan Pusat Statistik (BPS) pada gambar 1 menunjukkan p-ISSN 2301-9948 | e-ISSN 2407-6260 


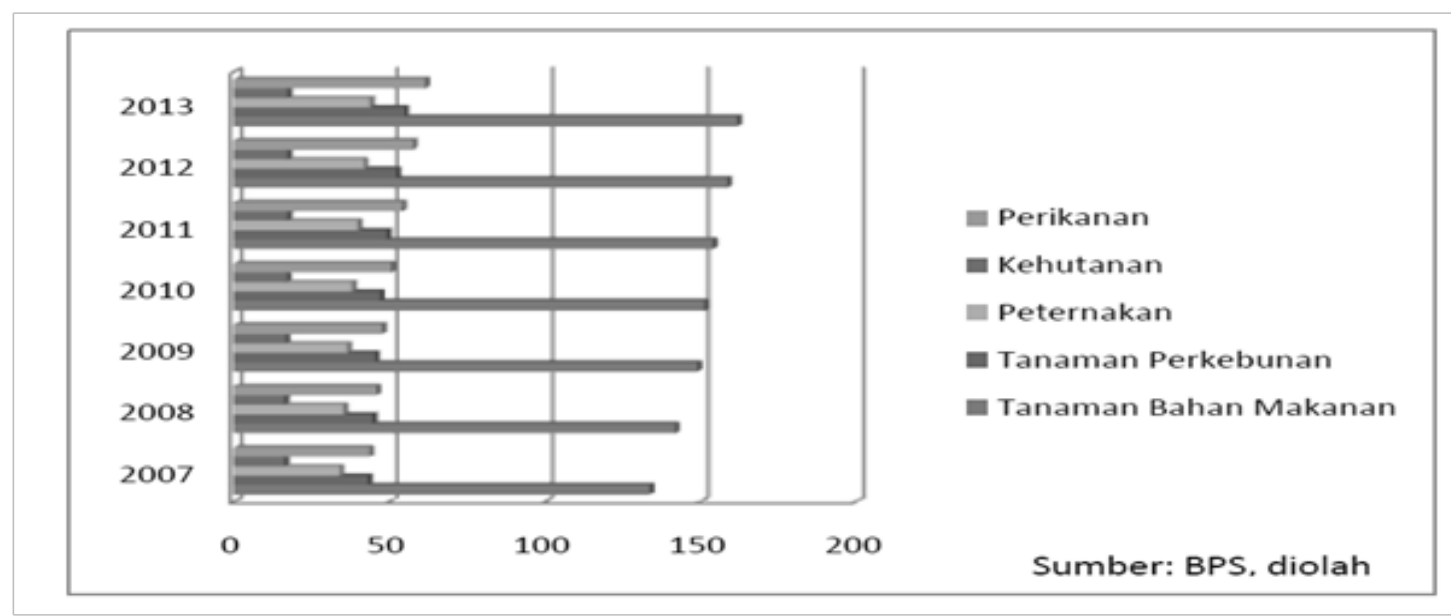

Sumber: BPS Diolah, 2014

\section{Gambar 1 \\ Kontribusi Sub-sektor Pertanian Tahun 2007-2013 (triliun Rupiah)}

bahwa subsektor perikanan merupakan subsektor terbesar kedua penyumbang PDB pada sektor pertanian setelah subsektor tanaman bahan makanan.

Berdasarkan data pada gambar 1 mensyiratkan bahwa subsektor perikanan merupakan subsektor yang penting dalam sektor pertanian dan selalu mengalami peningkatan setiap tahunnya. Hal tersebut dibuktikan dengan tingkat konsumsi ikan di Indonesia juga semakin meningkat dari tahun ke tahun. Menurut Kementrian Kelautan dan Perikanan Republik Indonesiamenyatakan bahwa trend konsumsi ikan selama tahun 20112015 menunjukkan peningkatan sebesar 6,27 persen dengan rata-rata konsumsi ikan sebesar $36,12 \mathrm{~kg} / \mathrm{kap} /$ tahun. Tercatat capaian angka konsumsi ikan pada tahun 2015 adalah sebesar 41,11 kg/kap/ tahun, melebihi target yang telah ditentukan sebesar 40,90 kg/kap/tahun. Adapun penyediaan konsumsi ikan untuk konsumsi domestik tahun 2014 mencapai 13,07 juta ton, meningkat sebesar 10,01 persen dibandingkan tahun 2013 (KKP, 2016).

Tingkat konsumsi ikan yang semakin meningkat maupun data terkait kontribusi sub-sektor perikanan yang menempati poisisi kedua setelah tanaman pangan menunjukkan bahwa pengembangan perikanan air tawar di Indonesia memiliki potensi yang cukup besar. Usaha tani dibidang perikanan air tawar memiliki prospek yang sangat baik karena sampai sekarang ikan konsumsi, baik berupa ikan segar maupun bentuk olahan, masih belum mencukupi kebutuhan konsumen (Bambang, 2001). Menjawab peluang yang ada dan didukung potensi yang dimiliki, Kabupaten Banyumas telah melaksanakan program Minapolitan sesuai dengan Keputusan Bupati Banyumas Nomor: 523/673/2008 sejak Tahun 2009 hingga saat ini. Konsep minapolitan itu sendiri adalah pengembangan wilayah yang menitik beratkan pada pengembangan komoditas-komoditas unggulan pada sektor perikanan di suatu wilayah. Tujuan pengembangan kawasan minapolitan adalah untuk mendorong percepatan pengembangan wilayah dengan kegiatan perikanan sebagai kegiatan utama dalam meningkatkan pendapatan dan kesejahteraan masyarakat dengan mendorong keterkaitan desa dan kota dan berkembangnya sistem dan usaha minabisnis yang berdaya saing berbasis kerakyatan, berkelanjutan dan terdesentralisasi di kawasan minapolitan (PERMEN No. 12 Tahun 2010). Perkembangan produksi budidaya pembesaran ikan di Kabupaten Banyumas cukup pesat dari tahun 2009 - 2011. Produksinya terus mengalami kenaikan walaupun belum mampu memenuhi target produksi pada tahun 2010 dan 2011 (Ru- 
diono, dkk., 2013).Disamping itu menurut Effendi dkk (2006) dan Hastuti dkk (2003) menyatakan Kabupaten Banyumas memiliki komoditas unggulan yang dikenal bernilai ekonomi penting dan harganya di pasar cukup tinggi serta sudah banyak dibudidayakan secara intensif yaitu ikan gurami.

Menurut data dari Dinas Perikanan Kabupaten Banyumas, pada tahun 2014 produksi benih ikan gurami mencapai 140.596.591 ekor dan ikan gurami konsumsi mencapai 4.060.089 ekor. Produksi ini adalah produksi tertinggi diantara budidaya komoditas ikan lainnya.Hal tersebut mensiratkan bahwa kegiatan agribisnis ikan gurami di Kabupaten Banyumas merupakan salah satu sumber pendapatan pembudidaya selain dari usaha lainnya. Lebih jauh lagi sesuai dengan dicanangkannya program minapolitan sesuai keputusan Bupati Banyumas Nomor: 523/673/2008 pembudidayan ikan gurami ini memiliki sentra di beberapa wilayah tertentu dan yang terbesar adalah Kecamatan Sokaraja lebih tepatnya di Desa Kalikidang yang di desain sebagai sentra pembesaran gurami (konsumi). Meski memiliki potensi akan pembesaran ikan gurami, pada penerapannya tidak terlepas dari berbagai permasalahan. Seperti komoditas pertanian maupun perikanan lainnya, struktur pasar yang terbentuk pada tingkat pedesaan menghadapi permasalahan seperti masalah permodalan, sarana prasarana, lemahnya posisi tawar petani/pembudidaya, harga selalu ditekan, masalah kualitas, dan rantai distribusi panjang sehingga terjadi penyusutan yang cukup signifikan.Sehingga salah satu cara yang dapat dilakukan adalah dengan memanfaatkan wadah yang dapat memperkuat posisi tawar yaitu dengan melalui Kelompok Pembudidaya Ikan (POKDAKAN) sebagai kelompok tani bagi pembudidaya ikan. Kelompok tani sebagai bagian dari masyarakat sipil mampu memberikan kesempatan untuk tindakan kolektif dan berpotensi memberdayakan dan mampu mendemokratisasikan pembangunan dan termasuk kelompok diabaikan (Mudege, dkk, 2015).
POKDAKAN bernama "Ulam Sari" yang berada di Desa Kalikiadang saat ini berperan sebagai lembaga yang bertujuan untuk memperkuat posisi tawar pembudidaya dengan melakukan manajemen khususnya pemasaran secara kolektif.Kegiatan ini dapat memperbaiki manajemen budidaya yang dilakukan pembudidaya hingga dapat memperbaiki mekanisme pemasaran yang adil sehingga tercipta kesejahteraan pembudidaya melalui peningkatan pendapatan. Penelitian ini bertujuan untuk mengetahui pola kerjasama antara POKDAKAN dengan pembudidaya ikan gurami. Kerjasama yang disoroti dalam penelitian ini terutama di bidang pemasaran.

\section{METODE PENELITIAN}

Penetian ini merupakan penelitian studi kasus dengan analisis deskriptif yang dilakukan di Desa Kalikidang Kecamatan Sokaraja Kabupaten Banyumas.Pemilihan tempat dilakukan secara purposive dengan pertimbangan Desa Kalikidang yang dikenal sebagai sentra pembesaran gurami terbesar di Kabupaten Banyumas. Sumber data adalah data primer dan data sekunder. Data primer diperoleh melalui wawancara langsung dengan pembudidaya gurami anggota POKDAKAN Ulam Sari dan pengurus POKDAKAN Ulam Sari. Sedangkan data sekunder diperoleh dari berbagai instansi terkait seperti BPS Kabupaten Banyumas, Dinas Perikanan, kantor kecamatan dan desa serta lembaga lain yang terkait.

Metode yang digunakan dalam menjawab dan menjelaskan tujuan adalah menggunakan analisis deskriptif (W Surakhmad 1998) dan metode pengumpulan data menggunakan metode wawancara, observasi serta pencatatan. Teknik wawancara digunakan untuk mengumpulkan data primer melalui wawancara langsung menggunakan daftar pertanyaan kepada narasumber yaitu pembudidaya pembesaran gurami dan stakeholder terkait. Teknik obserbasi dilakukan denganmengadakan pengamatan langsung terhadap 
objek yang diteliti sehingga memperoleh gambaran jelas terhadap kondisi lapang terutama pada model kerjasama POKDAKAN pada pemasaran agribisnis ikan gurami. Teknik pencatatan digunakan untuk mengumpulkan data sekunder yaitu data yang telah terlebih dahulu dikumpulkan dan dilaporkan oleh orang di luar peneliti. Data sekunder diperoleh dari Badan Pusat Statistik (BPS), POKDAKAM Ulam Sari dll. Data yang diperoleh kemudian disajikan menggunakan tabel dan bagan dengan mengetahui pola kerjasama POKDAKAN Ulam Sari dengan pembudidaya dalam mengelola usaha budidaya pembesaran ikan gurami.

\section{HASIL DAN PEMBAHASAN}

Pola Kerja Sama POKDAKAN Ulam Sari Kelompok Pembudidaya Ikan (POKDAKAN) Ulam Sari adalah salah satu POKDAKAN yang mewadahi para pembudidaya pembesaran ikan gurami di Desa Kalikidang. Pemfokusan pada pembesaran ikan gurami di Desa Kalikidang memiliki tujuan tertentu. Ibeh dkk (2006) menyatakan bahwa usaha agribisnis kecil harus fokus pada produk dan pasar tertentu untuk meningkatkan permintaan konsumen. Berawal dari program IDT (Indeks Desa Tertinggal) pada tahun 1999 hingga saat ini Ulam Sari memiliki kurang lebih 57 anggota. Anggota Ulam Sari dipersyaratkan harus dari warga sekitar khususnya yang tidak memiliki kolam dan modal untuk memulai usaha pembesaran ikan gurami. Sehingga nantinya dapat terbentuk kerjasama yaitu dengan pemberian bantuan terkait faktor-faktor produksi khususnya kolam, bibit, pakan, SDM untuk pengawasan dan manajemen.

Konsep kerjasama dan keuntungan timbal balik bagi kedua belah pihak (POKDAKAN dan anggota) seperti pada kelompok-kelompok tani lainnya hanya dalam kasus ini Ulam Sari lebih mendekati konsep Contract Farming/Kemitraan. Contract Farming sendiri menurut Wang dan Delgado (2014) memiliki banyak keuntungan seperti meminimalisir risiko rantai pasok, meningkatkan produktivitas pet- ani, merangsang 'kegiatan pemasaran, memfasilitasi petani akses ke pasar yang lebih tinggi, dan meningkatkan keuntungan total untuk kedua perusahaan (stakeholder yang memasok) dan petani. Selain itu konsep ini memiliki daya tarik untuk mempengaruhi partisipasi melalui pengetahuan, yang diperoleh melalui pendidikan, akses terhadap kredit dan kepastian tentangpersyaratan kebutuhan kontrak (Mwambi, dkk., 2014). POKDAKAN Ulam Sari melaksanakan konsep tersebut dengan cara yang lebih sederhana dan mencoba menerapkan sistem manajemennya denganprofessional seperti adanya farm record, pertemuan rutin, laporan cashflow, pemasaran bersama dan berbagai program lainnya. Dapat dikatakan bahwa tujuan utama dari POKDAKAN Ulam Sari adalah sebagai penguat posisi tawar pembudidaya dalam memanajemen usaha budidaya pembesaran ikan gurami.

Proses awal terjalinnya kerjasama dimulai dari kemauan seseorang untuk melakukan budidaya pembesaran ikan gurami namun terhalang oleh permodalan dan pemasaran. Secara personal hal tersebut dapat dikonsultasikan terlebih dahulu dengan pengurus Ulam Sari terkait langkah untuk menjadi anggota Ulam Sari hingga mampu mengakses permodalan. Selanjutnya pengurus Ulam Sari mengajukan syarat-syarat dan beberapa peraturan yang berlaku kepada calon anggota. Syarat yang harus dipenuhi seperti : 1) mengikuti anjuran dalam teknis budidaya agar sesuai dengan standard operasional procedure (SOP), 2) Pemasaran harus melalui kelompok, 3)Hasil pemasaran harus dibagi ke kelompok $15 \%$ dari keuntungan bersih setelah dikurangi biaya permodalan selama 6 bulan (2,5\%/bulan), 4) Mengikuti rapat rutin setiap satu bulan, 5) Mengikuti kegiatan yang diadakan oleh kelompok. Setelah calon anggota sepakat dengan syarat yang berlaku maka sebagai anggota akan memperoleh berbagai macam factor penunjang budidaya dari POKDAKAN Ulam Sari seperti : 1) Kolam budidaya, 2) Bibit ikan gurami, 3) pengarahan/pelatihan terkait budidaya pembesaran gurami me- 


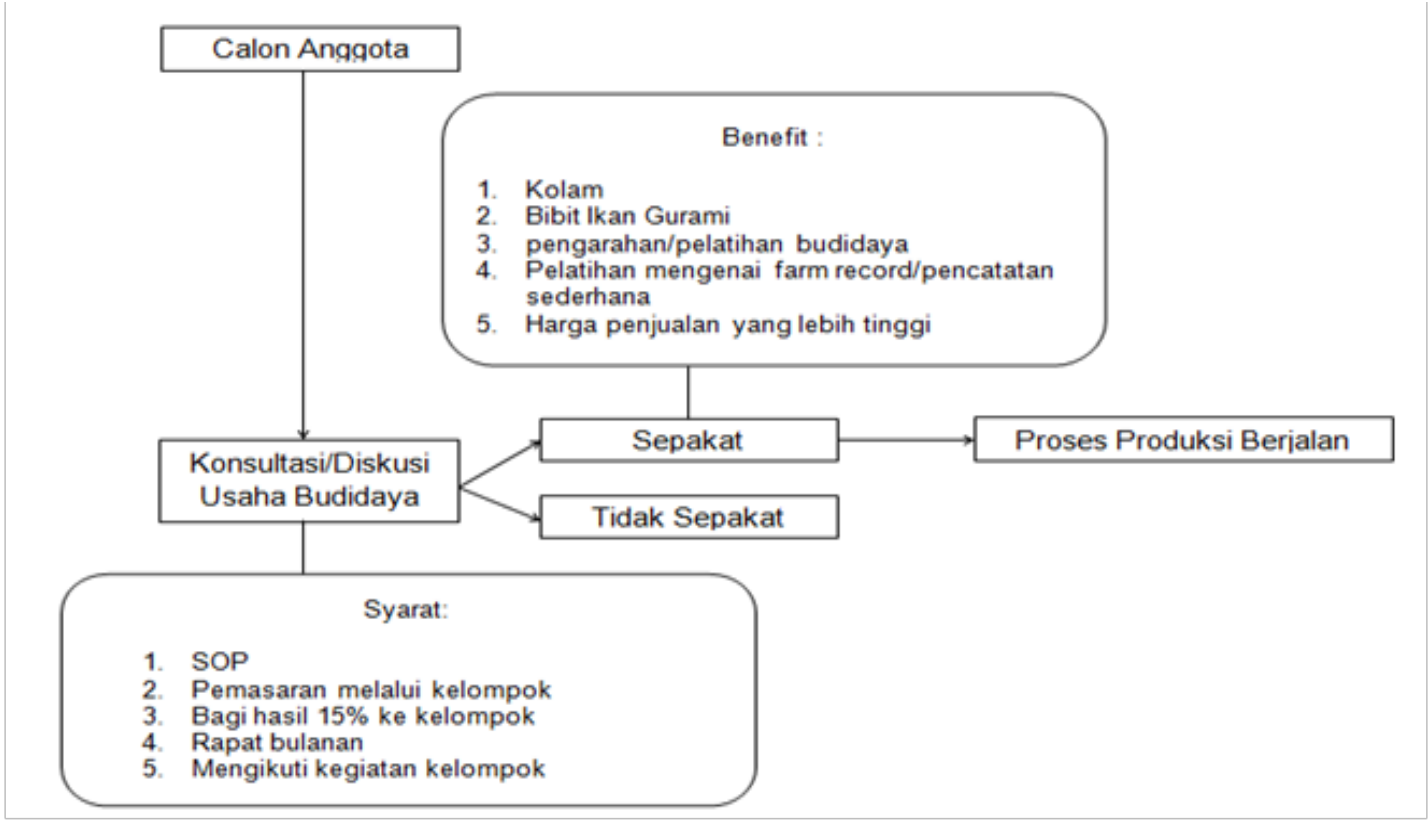

Sumber: Data Primer Diolah, 2015

\section{Gambar 2 \\ Alur Proses Keanggotaan}

lalui penyuluhan, 4) Pelatihan mengenai farm record/pencatatan sederhana terkait biaya yang dikeluarkan selama proses budidaya, 5) Harga penjualan yang stabil.

Apabila terjadi kesepakatan terjalinlah kerjasama antara Ulam Sari dengan pembudidaya sebagai anggota.Pada dasarnya anggota sangat diuntungkan karena hanya meluangkan waktu dan kemauan saja untuk memulai budidaya yang akhirnya akan menikmati hasilnya. Selebihnya berbagai macam faktor produksi telah disiapkan oleh POKDAKAN Ulam Sari.

\section{Manajemen Pemasaran POKDAKAN Ulam Sari}

Faktor penentu kesejahteraan pembudidaya lainnya selain produksi yaitu pemasaran.K Mahyuddin (2009), menyatakan bahwa pemasaran dapat diartikan sebagai suatu proses kegiatan menyalurkan produk dari produsen ke konsumen serta definisi lain mengatakan bahwa pemasaran terdiri dari kegiatan perorangan dan organisasi yang memudahkan dan mempercepat hubungan pertukaran yang memuaskan dalam lingkungan yang dinamis melalui penciptaan, pendistribusian, promosi dan penentuan harga barang, jasa serta gagasan(Mc Leod, dkk., 2004). Definisi tersebut secara implicit mengatakan bahwa pemasaran merupakan ujung tombak kegiatan ekonomi dalam bisnis khususnya agribisnis perikanan karena sebagai penghubung antara produsen dengan konsumen. Menurut Hingley dan Lindgreen (2002), menunjukkan pada dasarnya terdapat dua atau lebih aktor dalam hubungan bisnis yaitu pembeli yang mencari kepuasan akan kebutuhannya dan penjual yang menawarkan. Pada kerjasama yang terbentuk, POKDAKAN Ulam Sari sebagai penjual yang menawarkan barang (ikan gurami) kepada pembeli sesuai dengan permintaan baik secara kualitas maupun kuantitas sesuai dengan standard yang ditentukan bersama. Titik pentingnya adalah pemasaran oleh Ulam Sari dilakukan secara kolektif untuk meningkatkan posisi tawar pembudidaya supaya tidak dipermainkan oleh tengkulak. Pemasaran dilakukan sesuai schedule panen yang telah diatur pada tiap kolamnya agar tidak terjadi over 
production. Ketika pembeli tertarik dengan hasil panen ikan gurami, POKDAKAN Ulam Sari mensyaratkan untuk menggunakan jasa penen, timbang, dan angkut yang berasal dari internal POKDAKAN Ulam Sari. Harga jual yang ditawarkan kepada pembeli akan menjadi lebih tinggi Rp 1.500 - Rp $2.000 / \mathrm{kg}$ dari harga normal. Hal ini dilakukan sebagai langkah untuk menghindari permainan pembeli (tengkulak) yang terbiasa memainkan timbangan dan juga untuk mengefisiensikan biaya pasca panen.
Keuntungan bagi pembeli dengan pola kerjasama antara POKDAKAN dengan pembudidaya adalah memudahkan pembeli untuk mencari ikan gurami dalam satu tempat dengan kuantitas yang besar, kualitas yang terjamin dan keberlanjutan akan pemasaran. Sehingga pembeli tidak perlu mengeluarkan dana untuk mencari pembudidaya ikan gurami yang tersebar dari berbagai daerah dengan penawaran baru pada setiap transaksi.

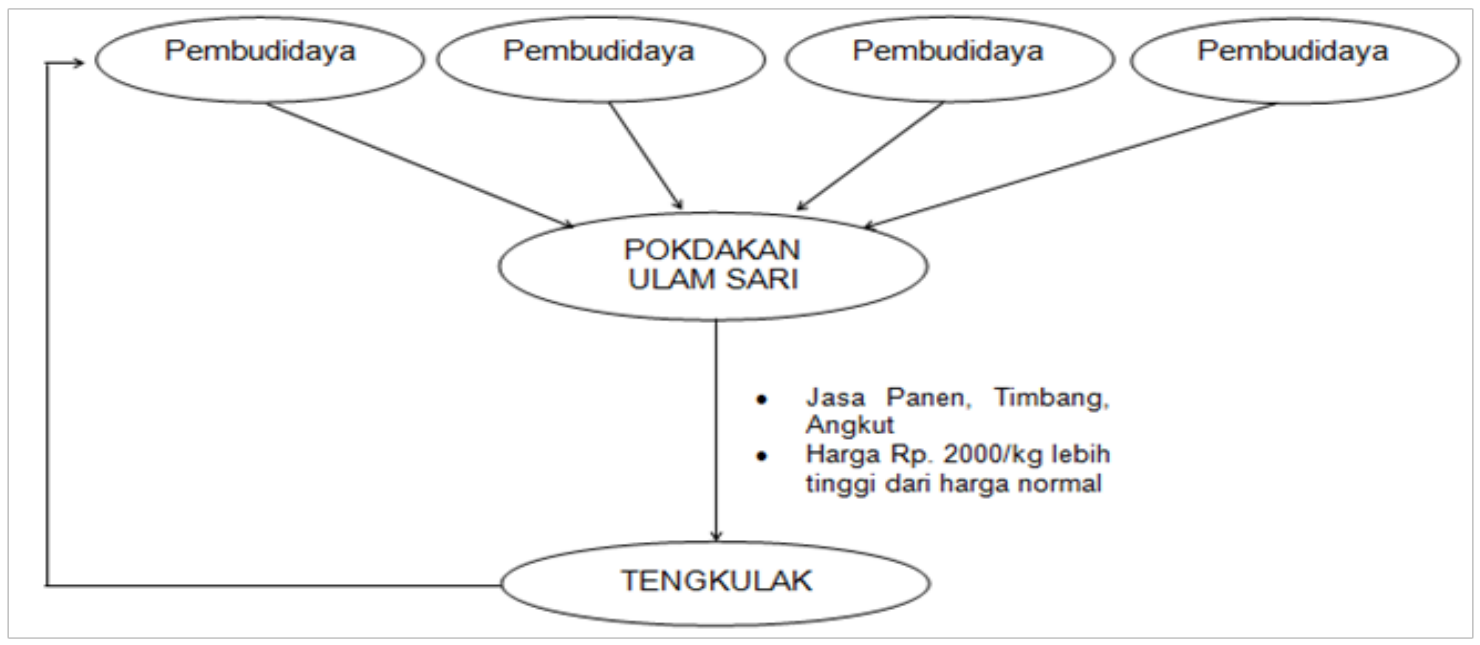

Sumber: Data Primer Diolah, 2015

\section{Gambar 3 \\ Mekanisme Pemasaran Melalui POKDAKAN Ulam Sari}

\section{Saluran Pemasaran}

Pada pembahasan mengenai pemasaran tidak terlepas dari saluran pemasaran. Saluran pemasaran merupakan penyaluran barang atau jasa dari produsen ke konsumen akhir dan yang menyelenggarakannya berupa lembaga atau badanbadan yang bertugas menjalankan fungsi pemasaran itu sendiri (Suarda, 2009). Organisasi yang dimaksud dapat berupa penjagal, grosir, agend dan distributor fisik (H Simamora, 2001). Berdasarkan gambar 4 dinyatakan bahwa saluran pemasaran ikan gurami konsumsi melalui POKDAKAN di Desa Kalikidang berawal dari pembudidaya yang menjual ikan gurami melalui POKDAKAN dimana POKDAKAN telah memiliki unit tersendiri untuk melakukan kegiatan pemasaran meliputi penetapan harga, teknis pemanenan hingga melay- ani calon pembeli. Hal ini dilakukan untuk meminimalisir kecurangan yang dilakukan pembeli saat pemanenan (penimbangan) serta menjaga stabilitas harga baik di musim hujan maupun musim kemarau.Saluran selanjutnya adalah dilakukan penjualan kepada beberapa pedagang pengepul. POKDAKAN Ulam Sari pada aspek pemasaran telah memiliki pelanggan dari pedagang pengepul tertentu sehingga sudah mengestimasi berapa kuantitas produksi bagi tiap-tiap pedagang pengepul. Pada tahap berikutnya pedagang pengepul menjual ke pedagang pengecer yang akan melanjutkan transaksi jual belinya dengan konsumen langsung. Sebagian transaksi pedagang pengepul juga dilakukan langsung dengan konsumen dengan harga yang berbeda ketika dilakukan dengan pedagang pengecer. 
1

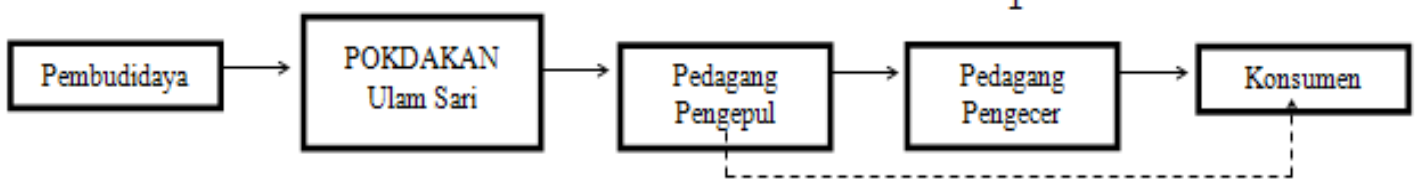

2

Sumber: Data Primer Diolah, 2015

\section{Gambar 4}

\section{Saluran Pemasaran Ikan Gurami Melalui POKDAKAN di Desa Kalikiding}

\section{SIMPULAN}

Melalui kerjasama antara POKDAKAN Ulam Sari dan pembudidaya ikan gurami diperoleh keuntungan 1) pembudidaya ikan gurami memperoleh ketersediaan faktor produksi seperti kolam, bibit, pakan dan SDM pengawasan; 2) POKDAKAN memperoleh ketersediaan ikan gurami konsumsi untuk dipasarkan dan keuntungan sebesar $15 \%$ dari hasil penjualan, 3) calon pembeli memperoleh barang (ikan gurami) dengan akses mudah (one spot service) dan memperoleh kualitas dan kuantitas yang diinginkan serta terjaganya kontinuitas pemasaran.Berdasarkan kondisi tersebut, untuk lebih meningkatkan kinerja POKDAKAN maka perlunya peran masif pemerintah pada pengembangan manajemen POKDAKAN demi mensejahterakan anggota POKDAKAN. Peran yang sangat diperlukan adalah terkait pembangunan pasar untuk menampung hasil panen ikan gurami dalam jumlah besar baik konvensional maupun melalui e-commerce serta aplikasi model yang telah terbukti berjalan pada POKDAKAN maupun kelompok tani lainnya supaya terjadi perkembangan pada agribisnis di masing-masing daerah. Hal ini senada dengan Isbandi dan S Rusdiana (2014), menyatakan peran pemerintah sangat mendesak sebagai strategi penguatan ketahanan pangan, mengingat krisis pangan akan berulang pada tahuntahun mendatang, sehingga perencanaan pembangunan pertanian (termasuk subsektor perikanan) membutuhkan political will dari pemerintah. Pertumbuhan POKDAKAN juga akan berdampak pada tumbuhnya karakter seorang wirausahawan pada pelaku agribisnis baik pengurus POKDAKAN maupun anggota. Menurut
Wibawa dan Charina (2014), karakter wirausahawan pada petani/pembudidaya mampu menciptakan cara pandang baru bahwa usahatani sebagai pemenuhan kebutuhan konsumen yang dapat memberikan keuntungan sertamenumbuhkan pola fikir kreatif bahwa untuk meningkatkan skala usaha tidak selalu dengan menambah modal tetapi dapat berkolaborasi dengan petani/pembudidaya lainnya.

\section{DAFTAR PUSTAKA}

Badan Pusat Statistik. 2014. Produk Domestik Bruto Menurut Lapangan Usaha. www.bps.go.id/pdb.php. Diakses tanggal 29 Januari 2015.

Bambang, A. 2001. Beberapa Metode Pembenihan Ikan Air Tawar. Yogyakarta. Kanisius.

Hastuti, S., Supriyono, E., Mokoginta I., \& Subandiyono. 2003. Respon Glukosa Darah Ikan Gurami (Osphronemus gouramy, LAC.) Terhadap Stres Perubahan Suhu Lingkungan. Jurnal Akuakultur Indonesia 2(2): 73-77.

Hingley, M., \& Lindgreen, A. 2002. Marketing of agricultural products: case findings. British Food Journal 104(10): 806-827.

I Effendi, H J Bugri, Widanarni.2006. Pengaruh padat penebaran terhadap kelangsungan hidup dan pertumbuhan benih ikan gurami osphronemus gouramy lac. Ukuran $2 \mathrm{~cm}$. Jurnal Akuakultur Indonesia 5(2): 127-135. 
Ibeh, K. I. N., Ibrahim, E., \& Panayides, P. M. 2006. International market success among smaller agri-food companies: Some case study evidence. International Journal of Entrepreneurial Behaviour \& Research, 12(2), 85-104.

Isbandi \& Rusdiana, S. 2014. Strategi Ketercapainya Ketahanan Pangan dalam Ketersediaan Pangan di Tingkat Regional. Agriekonomika 3(2): 116-131.

Kementrian Kelautan dan Perikanan Republik Indonesia. 2016. Konsumsi Ikan Naik dalam 5 Tahun Terakhir. http://kkp.go.id/2016/03/23/konsumsi-ikan-naik-dalam-5-tahunterakhir/. Diakses tanggal 26November 2016.

Mahyuddin, K. 2009. Panduan Lengkap Agribisnis Ikan Gurami. Penebar Swadaya. Jakarta.

McLeod, Jr. Raymond., George Schell. 2004. Sistem Informasi Manajemen, copyright (C) 2001. PrenticeHall,Inc. PT. Indeks. Jakarta.

Mudege, N. N., Nyekanyeka, T., Kapalasa, E., Chevo, T., \& Demo, P. (2015) Understanding collective action and women's empowerment in potato farmer groups in Ntcheu and Dedza in Malawi. Journal of Rural Studies 42: 91-101.

Mukti, G \& Charina, A. 2014. Penerapan Kewirausahaan dalam Pengelolaan Koperasi Agribisnis Berorientasi Bisnis. Agriekonomika 3(2): 192-203.

Mwambi, M. M., Oduol, J., Mshenga, P., \& Saidi, M. (2014). Does contract farming improve smallholder income? The case of avocado farmers in Kenya. Journal of Agribusiness in Developing and Emerging Economices 6(1): 2-20.

Peraturan Menteri Kelautan Dan Perikan- an Republik Indonesia Nomor 12 Tahun 2010 Tentang Minapolitan. 2010. Jakarta. Disalin sesuai dengan aslinya oleh Biro Hukum dan Organisasi.

Pujiastuti. 2012. Analisis Usaha Budidaya Ikan Gurami Di Kelompok Budidaya Ikan Mina Lestari Turus Tanjungharjo, Nanggulan Kulonprogo. AGRISE 21(2).

Rudiono, Harsasto P, Taufiq A. 2013. Evaluasi Pelaksanaan Program Minapolitan Tahun 2009 - 2011 di Kabupaten Banyumas. Jurnal IImu Pemerintahan tahun 2013.

Simamora, H. 2001. Manajemen Pemasaran Internasional. Jilid II. Salemba Empat. Jakarta.

Suarda, A. 2009. Saluran Pemasaran Sapi Potong di Sulawesi Selatan. Jurnal Sains \& Teknologi 9(2): 115-118.

Surakhmad W1998: Metode Penelitian. Penerbit Graha Indonesia. Jakarta.

Wang, H. , Wang, Y. , \& Delgado, M. (2014). The transition to modern agriculture: Contract farming in developing economies. American Journal of Agricultural Eco- nomics 96(5): 1257-1271. 